\title{
Size-dependent pattern of wildfire ignitions in Portugal: when do ignitions turn into big fires?
}

\author{
Francisco Moreira • Filipe X. Catry • \\ Francisco Rego $\cdot$ Fernando Bacao
}

Received: 25 August 2009/Accepted: 17 May 2010/Published online: 3 June 2010

(C) Springer Science+Business Media B.V. 2010

\begin{abstract}
Not all wildfire ignitions result in burned areas of a similar size. The aim of this study was to explore whether there was a size-dependent pattern (in terms of resulting burned area) of fire ignitions in Portugal. For that purpose we characterised 71,618 fire ignitions occurring in the country in the period 2001-2003, in terms of population density in the local parish, land cover type and distance to roads. We then assigned each ignition into subsets of five classes according to the resulting burned area: $>5$ ha, $>50$ ha, $>100$ ha, $>250$ ha, $>500$ ha. The probability of an ignition resulting in different burned area classes was modelled using binary logistic regression, and the relative importance, strength and signal (positive or negative) of the three explanatory variables compared across the models obtained for the different classes. Finally, we explored the implications of land cover and population density changes during the period 1990-2000 in Portugal for the likelihood of ignitions resulting in wildfires $>500$ ha. Population density was the more important variable explaining the resulting burned area, with the
\end{abstract}

F. Moreira $(\bowtie) \cdot$ F. X. Catry · F. Rego

Centre of Applied Ecology 'Prof. Baeta Neves', Institute of Agronomy, Technical University of Lisbon, Lisbon, Portugal

e-mail: fmoreira@isa.utl.pt

F. Bacao

Institute of Statistics and Information Management,

New University of Lisbon, Lisbon, Portugal probability of an ignition resulting in a large burned area being inversely related to population density. In terms of land cover, ignitions resulting in large burned areas were more likely to occur in shrubland and forest areas. Finally, ignitions farther away from roads were more likely to result in large burns. The current land cover trends (decrease of agricultural land and increase in shrublands) and population trends (decline in population densities except near the coast) are increasing the probability that ignitions will result in large fires in vast regions of the country.

Keywords Fire - Land cover - Accessibility · Population density $\cdot$ Landscape management

\section{Introduction}

Ignition risk (the chance of a fire starting as determined by the presence and activity of any causative agent, also defined as 'fire risk'; FAO 1986; NWCG 2006) is an essential element in assessing fire danger, which integrates the initiation, spread and difficulty of control of wildfires (e.g. Johnson and Miyanishi 2001; Vasconcelos et al. 2001; Chuvieco et al. 2003; Bonazountas et al. 2005; Finney 2005; Roloff et al. 2005; Vasilakos et al. 2007). Furthermore, understanding the factors driving the spatial patterns of fire ignitions has important implications for vigilance, fire 
fighting and prevention, public educational campaigns and the implementation of legislation concerning human activities prone to cause wildfires.

Numerous studies have identified several factors influencing the spatial patterns of fire ignitions (Chou 1992; Vega-Garcia et al. 1996; Cardille et al. 2001; Cardille and Ventura 2001; Vasconcelos et al. 2001; Mercer and Prestemon 2005; Genton et al. 2006; Nunes and Duarte 2006; Catry et al. 2007, 2009; Loboda and Csiszar 2007; Romero-Calcerrada et al. 2008). Among these, variables related to human activities are very important as, particularly in southern Europe, the vast majority of wildfires have human origin (EC 2008). For example in Portugal and Spain about $97 \%$ of all successfully investigated wildfires were human-caused (DGRF 2006; MMA 2007).

Once an ignition occurs the resulting burned area may differ widely in size, depending on several factors such as time lag until detection, weather conditions, fuel types, topography, fire intensity and rate of spread, time lag until fire fighting starts, or fire suppression effectiveness (e.g. Rothermel 1983; Mermoz et al. 2005; Moreira et al. 2009). Previous studies in Portugal (e.g. Rego et al. 2004) showed that the areas of the country with the highest density of ignitions do not coincide with those where larger fires occur. In fact, the vast majority of ignitions in Portugal and Spain result in very small burned areas and only a few turn into burned areas larger than 100 ha (Moreno et al. 1998; Bermudez et al. 2009). But the latter are the ones that will likely have significant ecological, economical and societal impacts, and efforts should be made in understanding which factors drive this particular type of ignition, that should be given priority in terms of fire prevention and suppression (before they get out of control and turn into large fires).

Few studies have addressed the size-related (in terms of resulting burned area) patterns of wildfire ignitions. Exceptions include the study of Preisler et al. (2004) for the Oregon state (USA), who found that the probability of an ignition turning into a large fire ( $>40$ ha) depended on the region, weather variables and vegetation type. Cardille et al. (2001) also found a higher likelihood of ignition resulting in large fire occurrence ( $>40 \mathrm{ha}$ ) in areas away from cities, near non-forest land cover, and with a lower lake and stream density. Other studies characterised the factors promoting the occurrence of large fires (e.g. Chuvieco et al. 1998; Cardille and Ventura 2001) but these did not include the analysis of characteristics of ignitions leading to these fires.

In a recent paper, Catry et al. (2009) explored the importance of population density, distance to roads, land cover type and elevation in determining fire ignition patterns in Portugal, in the period 2001-2005, by comparing ignition points and random locations. These authors have showed that population density was the main determinant of fire ignitions in the country, with a higher probability of ignitions in more populated areas, as found in other studies (e.g. Cardille et al. 2001; Mercer and Prestemon 2005). Land cover was the second most important variable, with the vast majority of ignitions being located in agricultural and urban-rural interspersed areas (85\%), and only $15 \%$ occurring in forested or uncultivated areas. This can be explained by the frequent use of fire in agricultural activities (e.g. burning harvest residues, maintaining pastures) and the high population densities and recreational activities in urban-rural interfaces, leading to negligent and accidental fires (e.g. barbecues, camp sites, cigarette butts). Elevation had a positive influence on the likelihood of ignitions and this could also be explained by the more frequent human use of fire at these elevations, for example for renovation of pastures for livestock (DGF 2003; MMA 2007) or higher frequency of lightning (Vazquez and Moreno 1998; Kilinc and Beringer 2007). Finally, distance to main roads had a negative influence on the likelihood of ignitions, meaning a decreasing probability of occurrence for increasing distance to roadways. In that study, $98 \%$ of ignitions occurred at less than $2 \mathrm{~km}$ from the nearest road and $85 \%$ were within a distance of $500 \mathrm{~m}$ (Catry et al. 2009). In short, the previous study concluded that wildfire ignitions were more likely to occur in areas with higher population density, closer to roads, and with a land cover of urban-rural areas and agricultural fields. However, in another paper, Catry et al. (2008) compared random locations with the ones of ignitions that have resulted in fires of different sizes and found that larger fires started more frequently in areas with low population density, longer distances to roads and in scrublands and forest areas. These discrepancies suggest that fire ignitions may have different characteristics, depending on whether they have become large or small burned areas.

In the current paper, we focus on ignition patterns by exploring what determines the resulting burned 
area, once an ignition occurs. Thus, we build upon the previous work of Catry et al. $(2008,2009)$ to explore the importance of the variables that may be influenced by human management (population density, land cover and distance to roads) as drivers of ignitions that resulted in wildfires of increasing size. The rationale for this is that the importance of the addressed variables may be different according to the resulting burned area, for example larger fires may start farther away from roads (which relates to accessibility), whereas for smaller-sized fires, land cover or population density may be the more important drivers. Thus, we sought to determine if there was a size-dependent pattern of fire ignitions in Portugal, and the relative importance of its drivers. To achieve this we compared the characteristics of five subsets of ignitions that resulted in increasing fire sizes, ranging from medium (the subset of ignitions that resulted in fires $>5$ ha) to large fires (the subset of ignitions that resulted in fires $>500$ ha), with the ones of the ignitions not included in that set. In particular, we aimed to answer the following questions: (a) is the relative importance of the three variables maintained when we analyse separate subsets of ignitions that turned into fires of increasing size?; (b) is the strength and direction of association (positive or negative) of the variables with ignition probability maintained in the different subsets? (c) which are the implications of recent (1990-2000) land cover and population density changes for the likelihood of ignitions resulting in large fires?

\section{Methods}

\section{Study area}

The study area is the whole Portuguese mainland, which covers about $90,000 \mathrm{~km}^{2}$ in southern Europe. Most part of the country is included in the Mediterranean biogeographic region and there is a transition to the Atlantic region in the north. Mean annual temperatures range from about $18^{\circ} \mathrm{C}$ in the south to $7^{\circ} \mathrm{C}$ at higher elevations in the north, and annual precipitation ranges from about $400 \mathrm{~mm}$ to $2800 \mathrm{~mm}$ (IA 2003). The elevation ranges from sea level to $2000 \mathrm{~m}$. About $48 \%$ of the country area is used for agriculture, while forests and shrublands cover about $27 \%$ and $19 \%$ respectively (DGF 2001). The population is estimated in about ten million inhabitants, more concentrated in the north and centre coastal areas (INE 2003).

Fire ignition database

We used the official wildfire database from the Portuguese Forest Services (DGRF), which contained the geographical coordinates and other characteristics (e.g. start and end date, resulting burned area) of all ignitions that occurred in Portugal between 2001 and 2003 (Fig. 1). In comparison with the dataset of Catry et al. (2009), the data used in the current paper relate only to ignition points (i.e. without random locations) and to a smaller subset of years.

Each ignition was classified into one or more of five classes of resulting burned area: $>5$ ha, $>50$ ha, $>100$ ha, $>250$ ha, $>500$ ha. Each ignition was coded in each class as a dummy variable (presence/ absence), so that it could take the value 0 (absence) in all classes, if it resulted in a burned area smaller than 5 ha, and the value 1 (presence) in all classes, if it had turned into a burn with over 500 ha. So, each class was a subset of ignitions from the previous one.

\section{Cartographic information}

All the spatial analysis and cartographic production were made using geographic information systems (GIS). Explanatory variable maps were produced for: (a) Population density - this map was obtained using a database from the National Statistics Institute concerning the 2001 Census (INE 2003), which included the number of persons present in each parish. This information was assigned to the official parish map (IGP 2004; vector format) and the population density (number of persons per $\mathrm{km}^{2}$ ) was calculated for each of the 4,050 parishes in the country; (b) Land cover-we used the Corine Land Cover 2000 cartography at scale 1:100,000 (IA 2005; vector format). The Portuguese cartography identifies 42 land cover classes which were grouped into six major classes according to their main characteristics: (1) agricultural areas, (2) forests, (3) shrublands (including some natural grasslands), (4) urban-rural interspersed areas (mostly areas where urban structures and other artificialized areas are interspersed with other land uses (mainly agriculture); continuous urban fabric represents less than $6 \%$ of the total area 

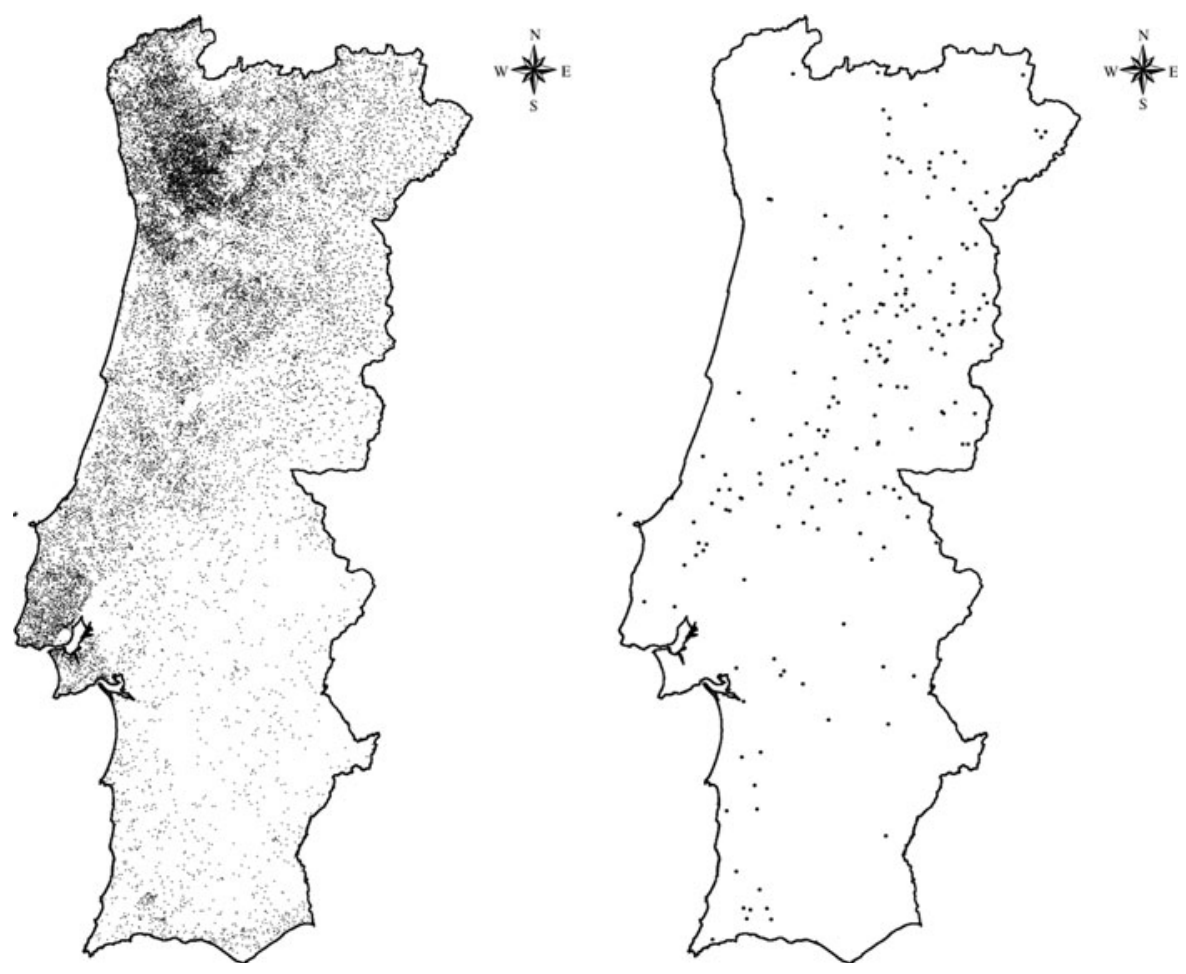

Fig. 1 Map of Portugal, showing the locations of all ignitions (left) and ignitions resulting in burned areas larger than 500 ha (right), for the period 2001-2003

of this class), (5) sparsely vegetated areas, and (6) wetlands (also including water bodies); (c) Distance to roads - this map was obtained using the Portuguese Itinerary Military Map in vector format at scale 1:500,000 (IGEOE 2005), representing the main national and regional roads. Distance (in meters) from each location of the territory to the nearest road was calculated, producing a raster map with $100 \mathrm{~m}$ spatial resolution that was resampled to $250 \mathrm{~m}$ using the bilinear interpolation method (ESRI 2005). For further details, see Catry et al. (2009).

The fire ignition database was transformed into a vector point map and overlayed with all the other maps in order to gather all the information in a single database, where each record contained the information of all the other layers.

In order to carry out a spatially explicit analysis of the implications of recent changes in land cover and population density on the occurrence of large fires (see "Data analysis"), a land cover and population density map were built for 1990/1991 based on data from the 1991 census (INE 1996) and the Corine Land Cover 1990 cartography at scale 1:100,000.
Data analysis

A very small proportion $(0.6 \%)$ of ignitions that occurred in sparsely vegetated areas and wetlands were excluded from the analysis, as we were interested in focusing on ignition patterns in the remaining four land cover types. For each class of resulting burned area, binary logistic regression (Hosmer and Lemeshow 1989) was used to find the relationships between the probability that an ignition fell within that class and the studied variables. The importance of each variable was assessed by the change in -2 Log Likelihood if the variable was removed from the model including all variables (this was expressed as a proportion of the $-2 \mathrm{Log}$ Likelihood of the model with all variables). Model performance was assessed through the likelihood ratio statistic and by calculating the area under the receiver operating characteristics (ROC) curve (Saveland and Neueschwander 1990; Pearce and Ferrier 2000). Land cover was analysed as categorical variable, using agricultural areas as the reference category (indicator contrast). As continuous variables were much skewed, 
they were $\log (x+1)$ transformed to approach normality and reduce variance before analyses.

For each variable, we used the non-parametric Spearman rank correlation to test the significance of trends between the value of the logistic regression coefficient for that variable and the rank order of resulting burned area classes. All analyses were carried out using SPSS software (SPSS 2006).

In order to spatialize each of the five logistic models obtained (one for each subset of ignitions), the three GIS layers were converted to a raster format and coregistered in a common base 250-m cell size. The model equation was then spatialized through map algebra operations in a GIS environment, in order to obtain the ignition probability map for each respective subset of resulting fire sizes. For each map, probabilities were rescaled to unity by dividing by the maximum expected probability in the model, and the four classes corresponding to the $0-0.25,0.25-0.50$, $0.50-0.75$ and $0.75-1.00$ intervals were plotted.

To evaluate the implications of recent changes in land cover and population density on the occurrence of very large fires (>500 ha), the logistic model obtained for this size category was run on the GIS layers corresponding to the 1990 situation. The difference between the 2 probability maps (1990 and 2000) were calculated through a map algebra operation and 4 categories of change (compared to 1990) were plotted: (1) decreased probability of more than $10 \%$ that an ignition would result in a fire $>500$ ha; (2) decreased probability of less than $10 \%$ that an ignition would result in a fire $>500$ ha; (3) increased probability of less than $10 \%$ that an ignition would result in a fire $>500$ ha; (4) increased probability of more than $10 \%$ that an ignition would result in a fire $>500$ ha. For all spatializations, non-significant logistic regression coefficients were assumed as nill.

\section{Results}

Frequencies of ignitions resulting in differentsized burned areas

During the period 2001-2003, 71,618 ignitions occurred in Portugal. The vast majority $(n=67,065$; $93.6 \%$ ) originated a burned area smaller than 5 ha. The subsets of ignitions originating burned areas larger than 5 ha, 50 ha, 100 ha, 250 ha and 500 ha had, respectively, 4,553 (6.4\%), 1,065 (1.5\%), $626(0.9 \%)$, $316(0.4 \%)$, and $182(0.3 \%)$ fires.

Relative importance of variables as a function of resulting burned area

All variables had significant contributions to all models $(P<0.05)$, except distance to roads in the models related to resulting burned areas larger than 250 ha (Fig. 2).

Model performance, as assessed by the area under the ROC curve (AUC), was reasonably good (AUC ranged from 0.744 to 0.852 ), with the value increasing from models related to ignitions resulting in smaller burns to models for ignitions resulting in larger burns. Once an ignition occurred, by far the most important variable determining the size of the resulting burned area, for all size classes, was population density (Fig. 2). Land cover and distance to roads had a much smaller importance. The importance of population density increased for ignitions resulting in fires larger than 50 ha (Fig. 2), compared to ignitions resulting in smaller burned areas, although the overall trend was not significant ( $\left.r_{\mathrm{s}}=0.30, P=0.624\right)$. Distance to roads tended to have lower importance as ignitions resulted in increasingly larger burned areas $\left(r_{\mathrm{s}}=-0.90\right.$, $P=0.037)$. In contrast, land cover seemed to have an increasing importance in models with ignitions resulting in larger burned areas, although the trend was not significant $\left(r_{\mathrm{s}}=0.70, P=0.188\right)$.

Direction of association of variables to ignition probabilities as a function of resulting burned area

The regression coefficient for population density was always negative, and significant, for all models (Fig. 3).

This means that once an ignition starts the likelihood of turning into a fire of at least 5 ha decreases as population density increases. As we focused on the subset of ignitions originating even larger fires, the coefficient got more negative, showing that for a given population density, the likelihood of having an ignition resulting in a given fire size decreased as a function of the resulting burned area (thus, ignitions which resulted in very large fires are more likely in regions of very low population density). This trend was significant $\left(r_{\mathrm{s}}=-1.00, P<0.0001\right)$. 

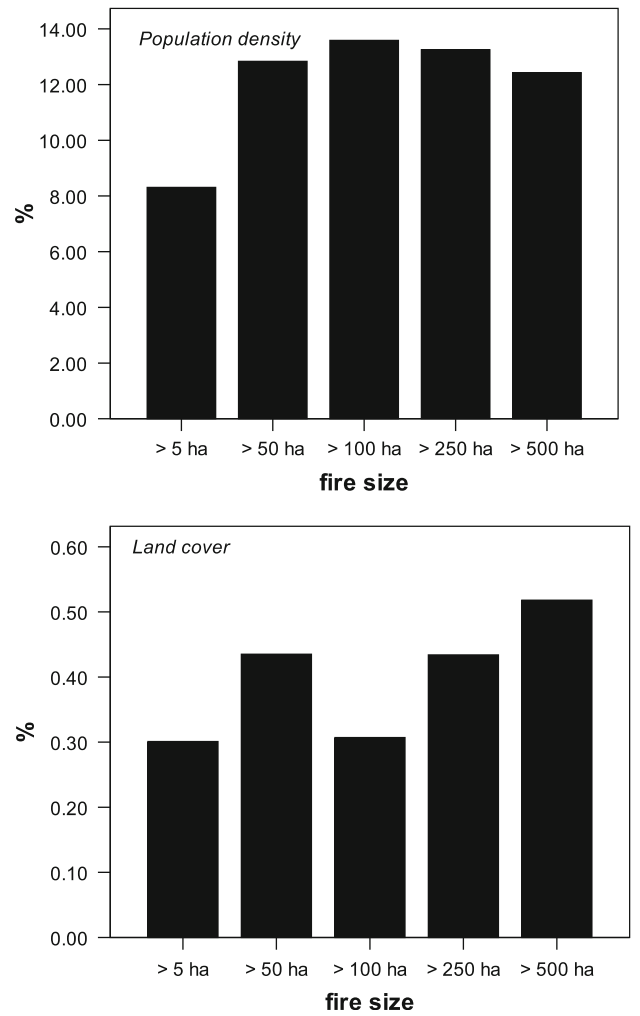

Fig. 2 Relative importance of population density, distance to roads and land cover in five logistic regression models expressing the likelihood of an ignition resulting in a burned area of different size classes. The importance of each variable is expressed as the change in $-2 \log$ Likelihood if the variable

For distance to roads, the coefficient was always positive with the exception of the model regarding ignitions resulting in burned areas larger than 500 ha (Fig 3). However, the contribution of this variable was not significant in both models dealing with ignitions originating burned areas over 250 ha. This shows that for medium-sized fires (5-250 ha) ignitions are more likely to occur further away from roads. There is no significant monotonic trend between the regression coefficient for this variable and the resulting burned area $\left(r_{\mathrm{s}}=-0.70, P=0.188\right)$.

For land cover, in comparison with agricultural areas, urban-rural interspersed areas are less likely to have ignitions resulting in burned areas over 5 ha (Fig. 3). For ignitions resulting in larger areas, there were no significant differences in occurrence probability between urban-rural and agricultural covers, although there was a systematic trend for an increase in the regression coefficient for the former $\left(r_{\mathrm{s}}=1.00\right.$, $P<0.0001)$. For forests and shrublands, ignitions

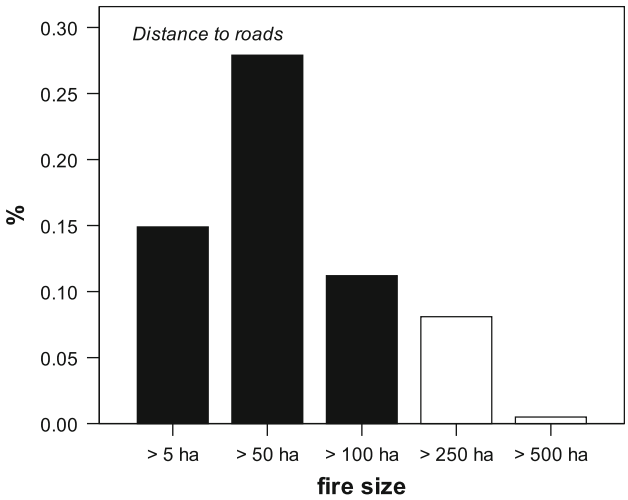

was removed from the model including all variables (expressed as the $\%$ of -2 Log Likelihood from the model including all variables). Non-significant changes are signalled as unfilled bars

resulting in larger burned areas were more likely to occur in these land covers than in agricultural areas, with a trend for this difference to increase as the resulting burned areas get bigger (for forests: $r_{\mathrm{s}}=0.90$, $P=0.037$; for shrublands: $\left.r_{\mathrm{s}}=0.70, P=0.188\right)$. For any given resulting burned area (over $5 \mathrm{ha}$ ), ignitions were always more likely in shrublands with the exception of larger fires (over 250 ha), where ignitions were equally likely in forested and shrubland areas.

Size-dependent ignition probability maps

The probability map for each category of resulting fire size is shown in Fig. 4. Two main patterns are evident: (1) the likelihood of an ignition resulting in a fire $>5$ ha is higher inland than along the coastal areas of Portugal, mainly in the northern and central part and in the Algarve region (in the south) (Fig. 4a); (2) overall, ignitions that could result in fires over 5 ha are more likely in the south of the country. If we 

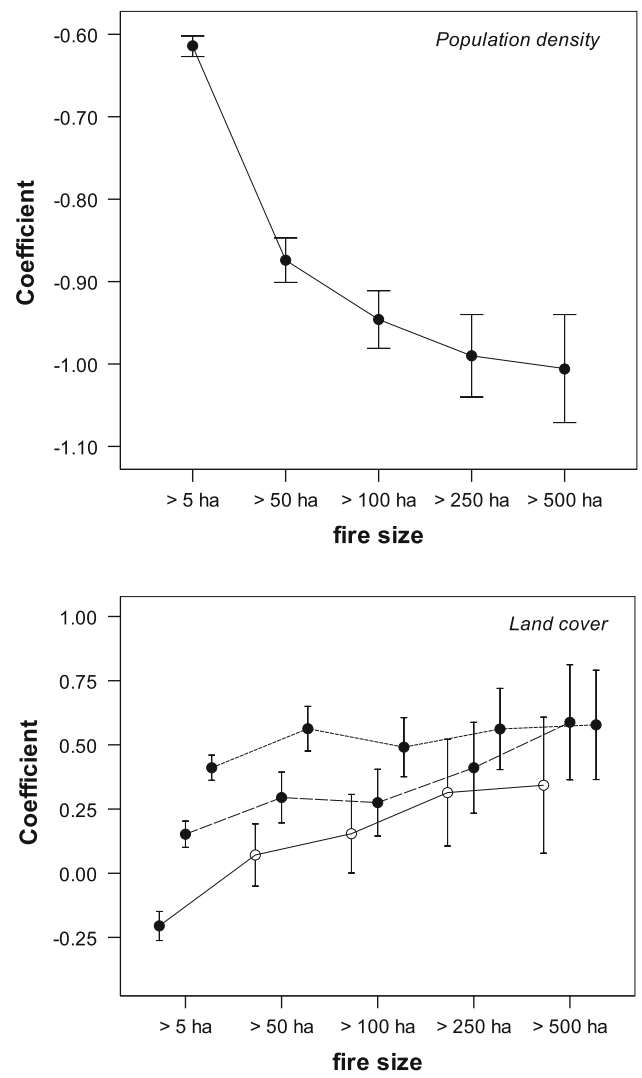

Fig. 3 Regression coefficients $( \pm \mathrm{SE}$ ) for each variable (population density, distance to roads and land cover) in different logistic regression models expressing the likelihood of an ignition resulting in a burned area of different size classes. Land cover is a categorical variable, with the reference

restrict the analysis to ignitions resulting in progressively larger fires (Fig. 4b-e), the regions of the country where they are more likely to occur become more restricted, concentrated along the east border with Spain and in the central region. These correspond to parishes where population density is particularly low (Fig. 5a).

Implications of land cover and population density changes on the likelihood of ignitions resulting in large fires

The land cover in 2000 was dominated by agricultural areas $(47.8 \%$ of the country), followed by forests $(27.3 \%)$, shrublands $(18.8 \%)$ and urban areas $(2.7 \%)$ (Fig. 5a).

The main land cover changes occurring during the period 1990-2000 were related to an increase in

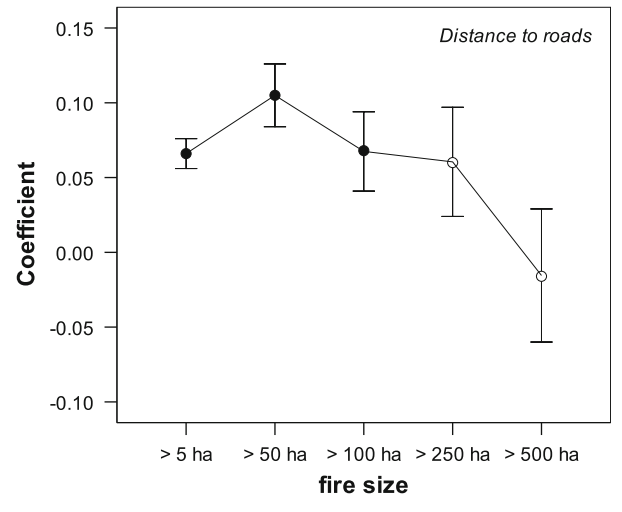

category being agricultural land. The upper (dotted), middle (dashed) and bottom lines represent, respectively, shrublands, forests and urban-rural interspersed areas. Non-significant regression coefficients are signalled as open dots

shrublands $(6.7 \%)$ and a decline in agricultural areas $(-4.3 \%)$. Forests $(-0.5 \%)$ and urban areas $(1.3 \%)$ had smaller changes. During the same period, a decline in population density was registered in many areas except along the coast and parts of Alentejo, where it generally increased (Fig. 5b). As a consequence, the likelihood of an ignition resulting in a very large fire ( $>500 \mathrm{ha}$ ) increased mainly in northeastern and central Portugal, and also in the Algarve mountains of southern Portugal (Fig. 5c). In contrast, it declined in the rest of the country.

\section{Discussion}

Population density was the more important variable determining the location of ignitions that resulted in larger burned areas in Portugal, and its importance 
Fig. 4 Relative probability of ignitions resulting in wildfires larger than (a) 5 ha, (b) 50 ha, (c) 100 ha, (d) 250 ha and (e) 500 ha, in Portugal. For each map, probabilities expected from the logistic regression models were rescaled to unity by dividing by the maximum value
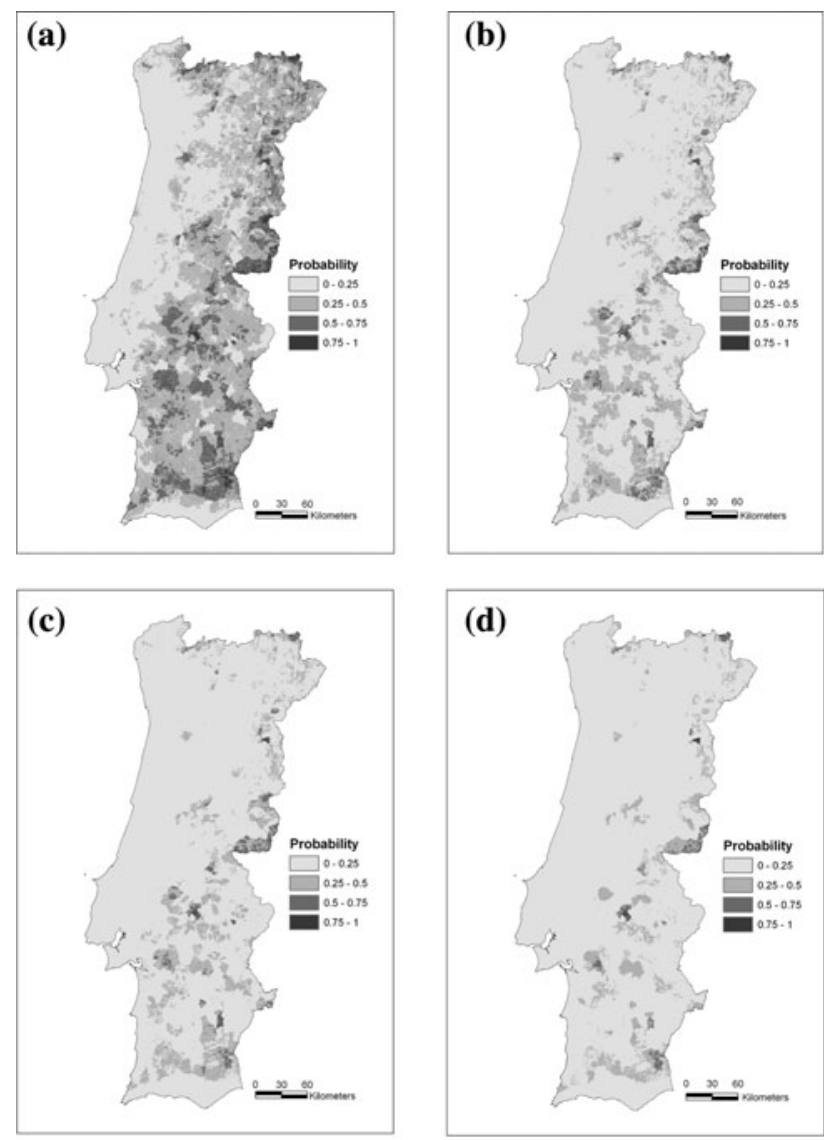

increased for ignitions turning into burns larger than 50 ha. Other studies have found a positive influence of this variable in determining fire starts, independently of the resulting burned area (e.g. Cardille et al. 2001; Mercer and Prestemon 2005; Yang et al. 2007). Similarly, Catry et al. (2009) found this variable to be the main determinant of wildfire ignitions in Portugal

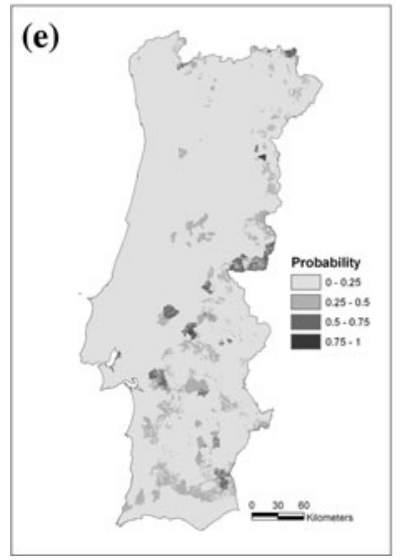

and with a similar relationship i.e. more ignitions in more densely populated areas. However, in the current study we found an inverse pattern, with increasing population density decreasing the likelihood that an ignition resulted in a large burned area. As a consequence, the resulting maps are quite distinct from the fire ignition risk map produced by 
Fig. 5 (a) Population density (number of persons per $\mathrm{km}^{2}$ ) (left) and land cover map (agricultural areas: black; forests: dark grey; shrublands: light grey; urban areas: white) (right) for Portugal. Data relate to the year 2000/2001 and were used to build the logistic models for each resulting fire size category.

(b) Population density changes during the period 1990-2000. (c) Change in the probability that an ignition would result in a fire larger than 500 ha, during the period 19902000
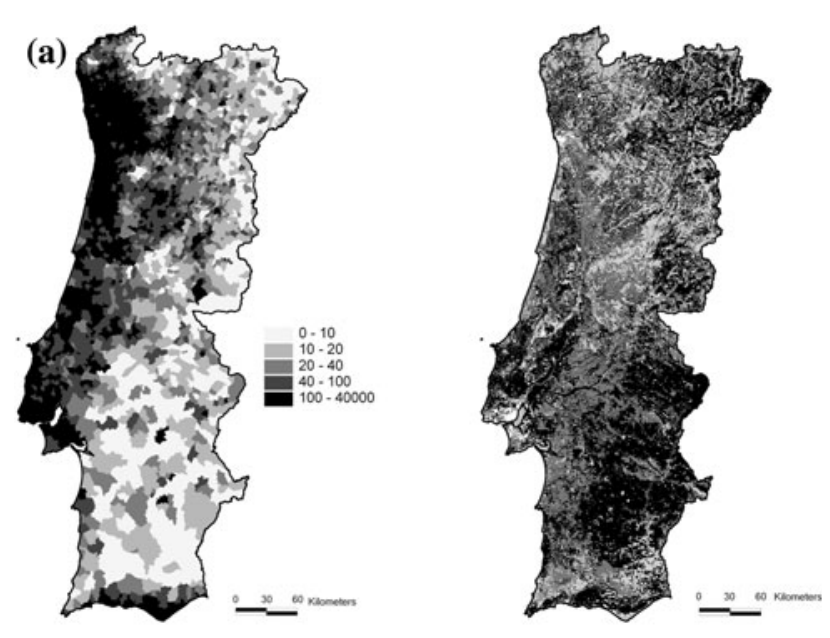

(b)

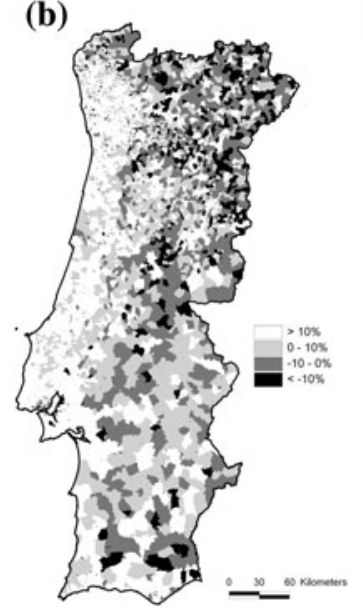

(c)

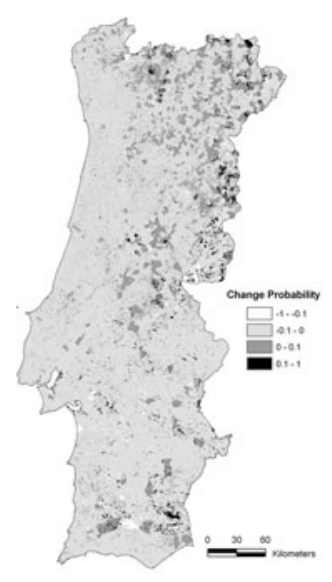

Catry et al. (2009). As we focus on the subset of ignitions resulting in increasingly larger fires (Fig. 4), the resulting probability maps become more concentrated in specific regions of particularly low population density. These results are consistent with the ones of Catry et al. (2008), who also found large fires to start in areas with comparatively lower population density. So, it seems that although population density is the main driver of fire ignitions, it may also the main driver controlling the subsequent fire spread that could result in large fires. Thus, there may be a dual role of population density on fire patterns, representing simultaneously a source of ignitions but maintaining the burned areas small, probably as a consequence of early detection after ignition, early attack, and more effective suppression, in more populated areas.
Land cover was the second most important variable, with its importance peaking for ignitions that resulted in burned areas larger than 500 ha. Other authors also found land cover to be an important determinant of wildfire ignitions (e.g. Cardille and Ventura 2001; Vasconcelos et al. 2001; Yang et al. 2007). Catry et al. (2009) found that in Portugal the vast majority of ignitions were located in agricultural and urban-rural interspersed areas (85\%), and only $15 \%$ occurred in forested or uncultivated areas, although they cover $50 \%$ of the country. This study showed that if a fire starts in forests and shrublands it is more likely to result in a larger burned area, which is consistent with the analysis carried out by Catry et al. (2008). Possible explanations for this difference include (a) a lower presence of people in these land cover types, which hinders early detection or 
suppression, (b) less effective fire fighting at the onset of fire, because of higher fuel loads that promote higher fire intensity and rate of spread, so that the fire gets out of control; (c) the fuel loads and spatial continuity of fuel, promoting fire spread, are usually higher in these land cover types.

Distance to roads had the lowest importance among the three studied variables. It seemed not to affect the probability of ignitions resulting in very large fires, but medium-size fires were more likely to occur farther away from roads. This contrasts with previous studies (e.g. Vega-Garcia et al. 1996; Romero-Calcerrada et al. 2008; Catry et al. 2009) that found a decreasing probability of ignitions with increasing distance to roadways. In Portugal, $98 \%$ of ignitions occurred at less than $2 \mathrm{~km}$ from the nearest road and $85 \%$ were within a distance of $500 \mathrm{~m}$ (Catry et al. 2009). The pattern found in the current study could be explained by a more difficult access and a lower human presence, which could contribute to longer time periods before fire detection and initial fighting. However, ignitions resulting in fires $>250$ ha seemed to occur independently of distance to roads.

Implications of land cover and population density changes on the likelihood of ignitions resulting in large fires

The observed population density changes during the decade 1990-2000 were characterised by a continuing trend for a population decline in inland areas and an increasing concentration of people along the coast (e.g. Ferrão 2004, Pinto Correia et al. 2006). This trend has been observed since the 1950s in different areas of the country, with significant impacts on land cover changes, most noticeably an increase in shrublands and forested areas at the expense of former agricultural and grazing lands (e.g. Moreira et al. 2001; Van Doorn and Bakker 2007). This same trend has been observed over large areas of the Iberian Peninsula, the so called "rural exodus syndrome" that is resulting in an increase in vegetation biomass over wide areas (Hill et al. 2008). In other regions of Europe, mainly in mountain areas, a similar pattern has been observed (MacDonald et al. 2000).

The implications of these landscape changes to increased fire hazard have been addressed in several studies. For example, the landscapes changes observed between 1958 and 1995 in a mountain region of northern Portugal have been estimated to represent a $20-40 \%$ increase in fuel accumulation at the landscape level (Moreira et al. 2001), with an inherent increase in fire hazard. Other studies also made this link between landscape changes and increased fire hazard in several Mediterranean areas (e.g. Debussche et al. 1999; Pérez et al. 2003; Mouillot et al. 2005; Moreira and Russo 2007; Hill et al. 2008).

Although our results suggest that current land cover and population density change trends are increasing the likelihood fire ignitions resulting in large fires in Portugal, recent published evidence does not suggest an increasing trend in the number of fires $>100$ ha in the country (Bermudez et al. 2009). Instead, a cyclic behaviour of extreme fire sizes is suggested by these authors, with a frequency of 3-5 years, probably driven by post-fire vegetation response dynamics, rather than meteorological or anthropogenic factors. Anyway, after 2000 several of the biggest burned patches in Portugal coincided with regions where ignitions resulting in such large fires were more likely. The main exception was the Alentejo region in southern Portugal, where areas with high probability have not so far registered large fires. We hypothesise that this may be a consequence of the existing very low population densities, the more important variable contributing to a higher likelihood that an ignition resulted in a large fire in our models, but a lack of land covers providing suitable fuel loads for fire spread. In fact, this region is still dominated by vast areas of farmland that, although suffering partial abandonment, do not represent homogeneous and continuous fuel patches as the ones existing in central and northern Portugal. However, policies promoting the afforestation of former agricultural land, coupled with abandonment and scrub encroachment (e.g. Pinto Correia 2006; Moreira and Russo 2007) may be quickly increasing the likelihood of large fires in a near future, in this region. Another explanation for the lack of large fires in the Alentejo, in spite of the potential for ignitions resulting in these large burns, may be the fact that the number of ignitions in southern Portugal is much lower than in the north (see Fig. 1), thus detection and initial suppression efforts are more effective in the latter region. 


\section{Conclusions}

Portugal is the southern European country with the highest density of fire ignitions, and ignition frequency has been increasing in the last years (EC 2008; Catry et al. 2009). A previous study (Catry et al. 2009) compared the characteristics of ignition locations with randomly located points, and found that wildfires were more likely to start in regions with higher population density, closer to roads, and in urban-rural interspersed areas or agricultural fields. However, most of these ignitions (over 90\%) resulted in very small burned areas (less than 5 ha). The current study showed that once an ignition occurs, there is a resulting fire size-dependent spatial pattern in the country, with the ones resulting in large fires being more likely in areas with low population density, in forest or shrublands, and usually farther away from roads. The current decline in population density in inland Portugal, due to population ageing and emigration to coastal areas, coupled with the abandonment of farming practices leading to shrub encroachment and forest expansion, add to the current expected climatic trends of less rainfall and hotter summers (Santos and Miranda 2006) to increase the likelihood that ignitions resulting in large fires will be more prevalent in the near future. This knowledge should be taken into account for the spatial allocation of resources, namely fire fighting personnel and equipment, for the definition of fire prevention (e.g. public campaigns) and suppression strategies, as well as for the definition of landscape management policies

Acknowledgements We acknowledge the Portuguese Forest Services (DGRF) for all collaboration and for providing the wildfire database. We also thank Paula Lopes, António Nunes and Vasco Nunes for their help on preliminary data processing. This study was supported by the European Commission under the 6th Framework Programme through the Integrated Project "Fire Paradox" (contract no. FP6-018505), by IFAP-IP through the Project "Recuperação de áreas Ardidas", and by Project FIRELAND (Project PTDC/AGR-CFL/104651/2008). FC was funded by Fundação para a Ciência e a Tecnologia (PhD grant SFRH/BD/65991/2009).

\section{References}

Bermudez Z, Mendes J, Pereira JMC, Turkman KF, Vasconcelos MJP (2009) Spatial and temporal extremes of wildfire sizes in Portugal. Int J Wildland Fire 18:983991

Bonazountas M, Kallidromitou D, Kassomenos PA, Passas N (2005) Forest fire risk analysis. Hum Ecol Risk Assess 11:617-626

Cardille JA, Ventura SJ (2001) Occurrence of wildfire in the northern Great Lakes Region: effects of land cover and land ownership assessed at multiple scales. Int J Wildland Fire 10:145-154

Cardille JA, Ventura SJ, Turner MG (2001) Environmental and social factors influencing wildfires in the Upper Midwest, USA. Ecol Appl 11:111-127

Catry FX, Damasceno P, Silva JS, Galante M, Moreira F (2007) Spatial distribution patterns of wildfire ignitions in Portugal. In: Proceedings of the 4th international wildland fire conference, Seville. CD Rom

Catry FX, Rego F, Moreira F, Bação F (2008) Characterizing and modelling the spatial patterns of wildfire ignitions in Portugal: fire initiation and resulting burned area. In: de las Heras J, Brebbia C, Viegas D, Leone V (eds) WIT transactions on ecology and the environment, vol 119. WIT Press, Toledo, Spain, pp 213-221

Catry FX, Rego F, Bação F, Moreira F (2009) Modelling and mapping wildfire ignition risk in Portugal. Int J Wildland Fire 18:921-931

Chou YH (1992) Management of wildfires with a geographical information system. Int J Geogr Inf Syst 6:123-140

Chuvieco E, Salas J, Barredo JI, Carvacho L, Karteris M, Koutsias N (1998) Global patterns of large fire occurrence in the European Mediterranean Basin: a GIS analysis. In: Viegas DX (ed) Proceedings of the 3rd international conference on forest fire research-14th conference on forest fire meteorology, vol II. ADAI, University of Coimbra, Portugal, pp 2447-2462

Chuvieco E, Allgöwer B, Salas J (2003) Integration of physical and human factors in fire danger assessment. In: Chuvieco E (ed) Wildland fire danger estimation and mapping. The role of remote sensing data, vol 4. World Scientific Publishing, Singapore

Debussche M, Lepart J, Dervieux A (1999) Mediterranean landscape changes: evidence from old postcards. Glob Ecol Biogeogr 8:3-15

DGF (2001) Inventário florestal nacional. Portugal continental. $3^{\text {a }}$ Revisão, 1995-1998. Direcção-Geral das Florestas, Lisboa

DGF (2003) Determinação das causas dos incêndios florestais em 2002. Direcção-Geral das Florestas, Lisboa

DGRF (2006) Incêndios florestais - Relatório de 2005. Divisão de Defesa da Floresta Contra Incêndios. Direcção-Geral dos Recursos Florestais (Lisboa)

EC (2008) Forest fires in Europe 2007. Report 8. European Commission, Joint Research Centre, Institute for Environment and Sustainability, Ispra, Italy, $80 \mathrm{pp}$

ESRI (2005) ArcGIS 9.1. software. Environmental Systems Research Institute, Redlands, CA

FAO (1986) Wildland fire management terminology. FAO Forestry Paper 70, Food and Agriculture Organization of the United Nations, $257 \mathrm{pp}$

Ferrão J (2004) Dinâmicas territoriais e trajectórias de desenvolvimento: Portugal 1991-2001. Revista de Estudos Demográficos 34:17-25 
Finney MA (2005) The challenge of quantitative risk analysis for wildland fire. For Ecol Manage 211:97-108

Genton MG, Butry DT, Gumpertz ML, Prestemon JP (2006) Spatio-temporal analysis of wildfire ignitions in the St Johns River Water Management District, Florida. Int J Wildland Fire 15:87-97

Hill J, Stellmes M, Udelhoven T, Röder A, Sommer S (2008) Mediterranean desertification and land degradation: mapping related land use change syndromes based on satellite observations. Glob Planet Change 64:146157

Hosmer DW, Lemeshow S (1989) Applied logistic regression. Wiley, New York

IA (2003) Atlas do Ambiente Digital. Instituto do Ambiente. Available at www.iambiente.pt/atlas/est/index.jsp [Verified 2 March 2007]

IA (2005) CORINE Land Cover 2000 Portugal. Instituto do Ambiente

IGEOE (2005) Carta Militar Itinerária de Portugal. Instituto Geográfico do Exército. Available at www.igeoe.pt [Verified 2 March 2007]

IGP (2004) Carta administrativa oficial de Portugal. Instituto Geográfico Português. Available at www.igeo.pt/igeo/ portugues/Frameset-egeo.htm [Verified 2 March 2007]

INE (1996) Censos 1991. Resultados definitivos. Instituto Nacional de Estatística

INE (2003) Dados estatísticos da população em Portugal Censos 2001. Instituto Nacional de Estatística

Johnson EA, Miyanishi K (2001) Forest fires: behavior and ecological effects. Academic Press, San Diego, CA

Kilinc M, Beringer J (2007) The spatial and temporal distribution of lightning strikes and their relationship. J Clim 20:1161-1173

Loboda TV, Csiszar IA (2007) Assessing the risk of ignition in the Russian Far East within a modelling framework of fire threat. Ecol Appl 17:791-805

MacDonald D, Crabtree JR, Wiesinger G, Dax T, Stamou N, Fleury P, Gutierrez Lazpita J, Gibon A (2000) Agricultural abandonment in mountain areas of Europe: environmental consequences and policy response. J Environ Manage 59:47-69

Mercer DE, Prestemon JP (2005) Comparing production function models for wildfire risk analysis in the wildlandurban interface. For Pol Econ 7:782-795

Mermoz M, Kitzberger T, Veblen TT (2005) Landscape influences on occurrence and spread of wildfires in Patagonian forests and shrublands. Ecology 86:2705-2715

MMA (2007) Los incendios forestales en España. Decenio 1996-2005. Area de Defensa Contra Incendios Forestales. Ministerio de Medio Ambiente, Madrid

Moreira F, Russo D (2007) Modelling the impact of agricultural abandonment and wildfires on vertebrate diversity in Mediterranean Europe. Landscape Ecol 22:1461-1476

Moreira F, Rego F, Ferreira P (2001) Temporal (1958-1995) pattern of change in a cultural landscape of northwestern Portugal: implications for fire occurrence. Landscape Ecol 16:557-567

Moreira F, Vaz P, Catry F, Silva JS (2009) Regional variations in wildfire preference for land cover types in Portugal: implications for landscape management to minimise fire hazard. Int J Wildland Fire 18:563-574
Moreno JM, Vázquez A, Vélez R (1998) Recent history of forest fires in Spain. In: Moreno JM (ed) Large forest fires. Backhuys, Leiden, pp 159-185

Mouillot F, Ratte J, Joffre R, Mouillot D, Rambal S (2005) Long-term forest dynamic after land abandonment in a fire prone Mediterranean landscape (central Corsica, France). Landscape Ecol 20:101-112

Nunes A, Duarte J (2006) Assessment of forest fire risk in the Serra da Estrela Natural Park (Portugal): methodological application and validation. In: Proceedings of the 5th international conference on forest fire research, Figueira da Foz. CD Rom

NWCG (2006) Glossary of wildland fire terminology. PMS 205, National Wildfire Coordinating Group

Pearce J, Ferrier S (2000) Evaluating the predictive performance of habitat models developed using logistic regression. Ecol Model 133:225-245

Pérez B, Cruz A, Fernández-González F, Moreno JM (2003) Effects of the recent land-use history on the postfire vegetation of uplands in Central Spain. For Ecol Manage 182:273-283

Pinto-Correia T, Breman B, Jorge V, Dneboská M (2006) Estudo sobre o abandono em Portugal continental. Análise das dinâmicas da ocupação do solo, do sector agrícola, e da comunidade rural.Tipologia de áreas rurais. Universidade de Évora, 226 pp

Preisler HK, Brillinger DR, Burgan RE, Benoir JW (2004) Probability based models for estimation of wildfire risk. Int J Wildland Fire 13:133-142

Rego FC, Catry FX, Maia MJ, Santos TA, Gravato A, Castro IC, Moreira FO, Pinto PR, Almeida J (2004) Análise da Rede Nacional de Postos de Vigia em Portugal. Technical Report, Lisboa

Roloff GJ, Mealey SP, Clay C, Barry J, Yanish C, Neuenschwander L (2005) A process for modelling short and longterm risk in the southern Oregon Cascades. For Ecol Manage 211:166-190

Romero-Calcerrada R, Novillo CJ, Millington JDA, GomezJimenez I (2008) GIS analysis of spatial patterns of human-caused wildfire ignition risk in the SW of Madrid (Central Spain). Landscape Ecol 23:341-354

Rothermel R (1983) How to predict the spread and intensity of forest and range fires. General Technical Report INT-143, Forest Service, United States Department of Agriculture, $161 \mathrm{pp}$

Santos FD, Miranda P (2006) Alterações climáticas em Portugal: Cenários, Impactos e Medidas de adaptação Project SIAM II. Gradiva, Lisbon

Saveland JM, Neueschwander LF (1990) A signal detection framework to evaluate models of tree mortality following fire damage. For Sci 36:66-76

SPSS (2006) SPSS for Windows. SPSS Inc., Chicago

Van Doorn A, Bakker M (2007) The destination of arable land in a marginal agricultural landscape in South Portugal: an exploration of land use change determinants. Landscape Ecol 22:1073-1087

Vasconcelos MJP, Silva S, Tomé M, Alvim M, Pereira JMC (2001) Spatial prediction of fire ignition probabilities: comparing logistic regression and neural networks. Photogramm Eng Remote Sens 67:73-81 
Vasilakos C, Kalabokidis K, Hatzopoulos J, Kallos G, Matsinos Y (2007) Integrating new methods and tools in fire danger rating. Int J Wildland Fire 16:306-316

Vazquez A, Moreno JM (1998) Patterns of lightning- and human-caused fires in peninsular Spain. Int $\mathbf{J}$ Wildland Fire 8:103-115
Vega-Garcia C, Lee BS, Woodard PM, Titus SJ (1996) Applying Neural Network technology to human-caused wildfire occurrence prediction. Art Int Appl 10:9-18

Yang J, Healy HS, Shifley SR, Gustafson EJ (2007) Spatial patterns of modern period human-caused fire occurrence in the Missouri Ozark Highlands. For Sci 53:1-15 